Background: Takayasu arteritis (TA) is a chronic granulomatous large-vessel vasculitis most commonly seen in women under 50 years of age[1]. The pulmonary arteries are less often involved, with the frequency of involvement varying widely between countries (from $4 \%$ to $>50 \%$ ) [2-5]. Respiratory symptoms or signs and pulmonary imaging findings in TA have not been fully investigated [6-7]. Objectives: This study aimed to describe pulmonary high-resolution computed tomography (HRCT) findings in TA and to determine possible causes.

Methods: A total of 243 TA patients were enrolled from a prospective cohort after excluding 260 patients with other pulmonary disorders or incomplete data. Clinical data including symptoms, lab results, imaging information were collected. Pulmonary HRCT were interpreted by two radiologist who were blinded to patients' clinical information. Abnormal pulmonary features were recorded as nodules, stripe opacity (linear opacity), patchy opacity, ground-glass opacity, pleural thickening, pleural effusion, pulmonary infarction, mosaic attenuation, pulmonary bronchiectasis, pulmonary oedema. After evaluation, patients were divided into two groups: those with normal lung HRCT and those with abnormal lung HRCT. Clinical characteristics were compared between groups and binary logistic regression analysis was applied to identify potential risk factors for the lung lesions. Follow-up HRCT (obtained in 64 patients) was analysed to study changes in pulmonary lesions after at least 6 months' treatment.

Results: Of the 243 patients, 107 (44.0\%) had normal lung HRCT while 136 (56.0\%) had abnormal lung HRCT, including stripe opacity $(60.3 \%)$, nodules $(44.9 \%)$, patchy opacity $(25.0 \%)$, pleural thickening $(15.4 \%)$, pleural effusion $(10.3 \%)$, ground-glass opacity $(8.1 \%)$, pulmonary infarction $(6.6 \%)$, mosaic attenuation $(4.4 \%)$, bronchiectasis $(3.7 \%)$, and pulmonary oedema $(2.2 \%)$. Patients with abnormal HRCT were significantly more likely to have type II arterial involvement $(25 \%$ vs. $12.2 \%, P=0.04)$, pulmonary arterial involvement (PAl; $21.3 \%$ vs. $5.6 \%, P<0.001)$, pulmonary hypertension $(20.6 \%$ vs. $8.4 \%, P=0.01)$, and abnormal heart function $(27.9 \%$ vs. $7.6 \%, \mathrm{P}<0.001)$. Logistic regression analysis demonstrated that $\mathrm{PAI}(\mathrm{OR}=3.0,95 \% \mathrm{Cl}=1.1-8.4, \mathrm{P}=0.03)$, worsened heart function $(\mathrm{OR}=2.7,95 \% \mathrm{Cl}=1.1-6.6, \mathrm{P}=0.03)$, and age $(\mathrm{OR}=1.1,95 \% \mathrm{Cl}=$ $1.0-1.1, P<0.01)$ were associated with presence of pulmonary lesions. Pulmonary infarction, pleural effusion, and patchy opacities improved partially after treatment. Conclusion: Pulmonary lesions are not rare in patients with TA. Age, PAI, and worsened heart function are potential risk factors for presence of pulmonary lesions in TA.

REFERENCES:

[1] Jennette JC, Falk RJ, Bacon PA, et al. 2012 Revised International Chapel Hill Consensus Conference Nomenclature of Vasculitides. Arthritis Rheum 2013;65:1-11.

[2] Kong X, Ma L, Wu L, et al. Evaluation of clinical measurements and development of new diagnostic criteria for Takayasu arteritis in a Chinese population. Clin Exp Rheumatol. 2015; 33(2 Suppl 89): S-48-55.

[3] Nooshin D, Neda P, Shahdokht S, Ali J. Ten-year Investigation of Clinical, Laboratory and Radiologic Manifestations and Complications in Patients with Takayasu's Arteritis in Three University Hospitals. Malays J Med Sci. 2013; 20(3):44-50.

[4] Bicakcigil M, Aksu K, Kamali S, et al. Takayasu's arteritis in Turkey - clinical and angiographic features of 248 patients. Clin Exp Rheumatol. 2009; 27(1 Suppl 52):S59-64.

[5] Kechaou M, Frigui M, Ben Hmida M, Bahloul Z. Takayasu arteritis in Southern Tunisia a study of 29 patients. Presse Med. 2009; 38(10):1410-4.

[6] Dou JB, Gong JN, Ma ZH, Kuang TG, Yang YH. The analysis of the clinical records diagnosed as Takayasu's arteritis with pulmonary vascular involvement. Zhonghua Jie He Hu Xi Za Zhi. 2016; 39(8):603-7.

[7] Nd Perera G, C Jayasinghe A, D Dias L, Kulatunga A. Bronchiectasis and hoarseness of voice in takayasu arteritis: a rare presentation. BMC Res Notes. 2012; 5:447.

Disclosure of Interests: None declared

DOI: 10.1136/annrheumdis-2021-eular.2789

\section{EULAR RECOMMENDATIONS ON GIANT CELL ARTERITIS IN REAL LIFE}

F. Regola ${ }^{1}$, F. Franceschini ${ }^{1}$, G. Bosio ${ }^{2}$, P. Toniati ${ }^{1} .{ }^{1}$ ASST Spedali Civili and University of Brescia, Rheumatology and Clinical Immunology Unit, Brescia, Italy; ${ }^{2}$ ASST Spedali Civili of Brescia, Nuclear Medicine Unit, Bresica, Italy

Background: GCA is the most frequent systemic vasculitis in patients older than 50 years involving medium-sized and large arteries. On July 2019 EULAR published its updated recommendations for the management of large vessel vasculitis, including GCA.

Objectives: To analyze how the application of the updated EULAR recommendations changed clinical practice in GCA patients in our Hospital.

Methods: All patients with a new diagnosis of GCA between January $1^{\text {st }}, 2018$ and December $31^{\text {st }}, 2020$ were enrolled in this study. Two cohorts were analyzed: patients who received GCA diagnosis in the eighteen months before EULAR recommendations publication (between January $1^{\text {st }}, 2018$ and June $30^{\text {th }}, 2019$ : cohort A) and patients who received GCA diagnosis in the following eighteen months (between July $1^{\text {st }}, 2019$ and December $31^{\text {st }}, 2020$ : cohort B). Data are expressed as median (IQR).

Results: 70 patients were enrolled in the study (F: 47, M: 23, age: 76 (69-79) years): 39 patients in cohort A, 31 in cohort B. Table 1 summarize main clinical features and treatment of patients. Sixteen patients of cohort $A(41 \%)$ and eleven patients of cohort B (35\%) presented large vessel involvement demonstrated by FDG-PET/CT. Thirty-one patients in cohort A (79\%) and twenty-seven in cohort B $(87 \%)$ presented cranial symptoms and were studied with temporal arteries ultrasound (US) and/or biopsy (TAB). More specifically, in cohort A US was performed in $42 \%$ of patients with cranial symptoms and TAB in $58 \%$ of them. After EULAR recommendations publication (cohort $B$ ) the percentage of patients with cranial symptoms who performed US increased to $56 \%$ and the percentage of TAB decreased to $52 \%$.

After EULAR recommendations publication, time between symptoms onset and first rheumatologic evaluation was reduced by $30 \%$ (from 61 (23-131) to 43 (2292) days)

No difference in treatment regiments were found between groups, whether in glucocorticoid initial dose or DMARDs adjunctive therapy.

Conclusion: After EULAR recommendations publication, two major improvement were achieved in our cohort. EULAR suggests GCA patients should be urgently referred to a specialist team. Consistently with this recommendation time between symptoms onset and first rheumatologic evaluation was markedly reduced. Moreover, EULAR suggests always confirming GCA diagnosis by imaging or TAB, with US as first choice. In line with these recommendations, in our cohort US became more and more frequently performed and progressively preferred over TAB. On the other hand, no differences in treatment regiments were found over time, with EULAR recommendations satisfied both before and after their publication.

\section{REFERENCES:}

[1] Hellmich B, et al. Ann Rheum Dis 2019

\begin{tabular}{lccc}
\hline & $\begin{array}{c}\text { ALL GCA } \\
\text { (n: } 70)\end{array}$ & $\begin{array}{c}\text { Before EULAR } \\
\text { recommendations } \\
\text { (n: 39) }\end{array}$ & $\begin{array}{c}\text { After EULAR } \\
\text { recommenda- } \\
\text { tions (n: 31) }\end{array}$ \\
\hline $\begin{array}{l}\text { Time between symptoms onset and first } \\
\text { rheumatologic evaluation (days) }\end{array}$ & $53(22-110)$ & $61(23-131)$ & $43(22-92)$ \\
$\begin{array}{l}\text { Temporal artery US } \\
\begin{array}{l}\text { Temporal artery biopsy } \\
\text { Large vessel involvement (FDG-PET/CT) }\end{array}\end{array}$ & $\begin{array}{c}28 / 58(48 \%) \\
27(39 \%)\end{array}$ & $\begin{array}{c}13 / 31(42 \%) \\
16 / 31(58 \%)\end{array}$ & $\begin{array}{c}15 / 27(56 \%) \\
14 / 27(52 \%)\end{array}$ \\
$\begin{array}{l}\text { Glucocorticoid initial dose (mg/die pred- } \\
\text { nisone equivalent) }\end{array}$ & $50(47-50)$ & $50(50-50)$ & $50(38-50)$ \\
\begin{tabular}{l} 
DMARDs \\
\hline
\end{tabular} & $43(61 \%)$ & $24(61 \%)$ & $19(61 \%)$ \\
\hline
\end{tabular}

Disclosure of Interests: None declared

DOI: 10.1136/annrheumdis-2021-eular.2971

\section{POS0812 SUBCLAVIAN ARTERIES INVOLVEMENT IN PATIENTS WITH GIANT CELL ARTERITIS: DO WE NEED A MODIFIED HALO SCORE?}

J. Molina Collada ${ }^{1}$, J. Martínez-Barrio ${ }^{1}$, B. Serrano-Benavente ${ }^{1}$, I. Castrejon ${ }^{1}$, J. C. Nieto González ${ }^{1}$, L. R. Caballero Motta ${ }^{1}$, L. Trives Folguera ${ }^{1}$, J. M. AlvaroGracia'. ${ }^{1}$ Hospital General Universitario Gregorio Marañón, Rheumatology, Madrid, Spain

Background: EULAR recommendations propose temporal and axillary arteries ultrasound (US) as first-line investigation when predominantly cranial giant cel arteritis (GCA) is suspected. Recently, two novel US scoring systems, the halo count and the Southend Halo Score, have been developed to quantify the extent of inflammation by US in GCA.

Objectives: To assess whether adding the subclavian arteries examination into the ultrasound (US) Southend Halo Score, as proposed in the modified Halo Score, improves the diagnostic accuracy of GCA and its relationship with systemic inflammation

Methods: Retrospective observational study of patients referred to a GCA fas track pathway (FTP) over a 1-year period. Patients underwent US exam of temporal and large vessel (LV) (carotid, subclavian and axillary) arteries. The extent of inflammation was measured by the halo count, the Southend Halo Score and the modified Halo Score (Image 1). The gold standard for GCA diagnosis was clinical confirmation after 6 months follow-up.

Results: 64 patients were evaluated in the FTP, 17(26.5\%) had GCA. Subclavian arteries involvement was present only in patients with GCA $(29.4 \%$ versus $0 \%, p<0.001$ ) (Table 1). Overall, the three scores showed excellent diagnostic accuracy for GCA (ROC AUC 0.906, 0.930 and 0.928 , respectively) and moderate correlations with acute phase reactants $(0.35-0.51, p<0.01)$. However, in the subgroup of patients presenting LV involvement, moderate correlations were 
found between the modified Halo Score and ESR (rho 0.712, $p<0.05$ ), haemoglobin (rho 0.703, $p<0.05$ ) and platelets (rho 0.734, $p<0.05$ ), but not with the other two US scores.

\section{A. HALO COUNT}

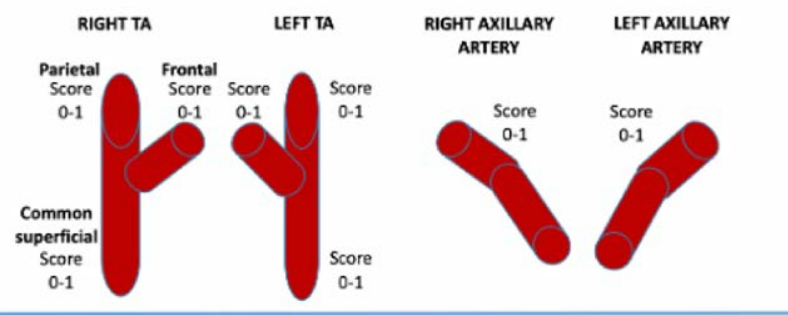

\section{B. HALO SCORE}

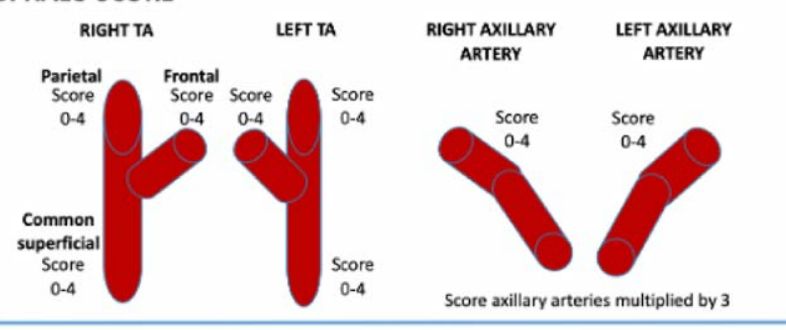

\section{MODIFIED HALO SCORE RIGHT AXILLARY ARTERY LEFT AXILLARY ARTERY}

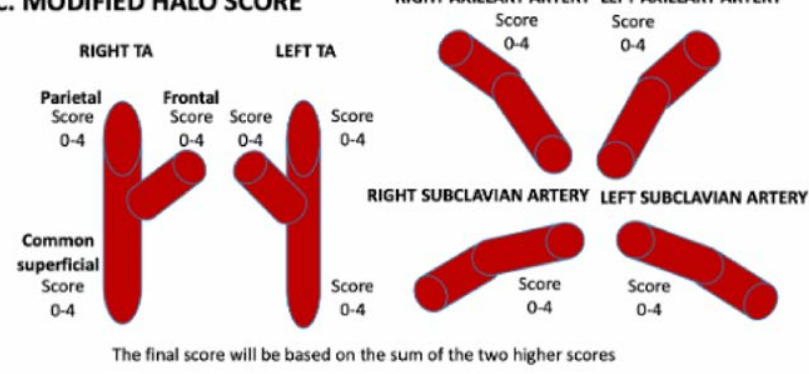

Figure 1. Proposed scores to quantify the extent of vascular inflammation by ultrasound in giant cell arteritis. A. Halo count, B. Halo Score, C: Modified Halo Score

Table 1. Clinical, laboratory and ultrasound findings of patients included in the fast track pathway with or without GCA clinical confirmation.

\begin{tabular}{|c|c|c|c|c|}
\hline & $\begin{array}{l}\text { Total } \\
n=64\end{array}$ & $\begin{array}{c}\text { Patients } \\
\text { with GCA } \\
n=17\end{array}$ & $\begin{array}{c}\text { Patients } \\
\text { without GCA } \\
\qquad n=47\end{array}$ & p \\
\hline Age, median (IQR) & $\begin{array}{cc}78 & 7 \\
(69.3-83)\end{array}$ & $78(72.5-83)$ & $78(66-83)$ & 0.5 \\
\hline Female, $\mathrm{n}(\%)$ & $42(65.6 \%)$ & $10(58.8 \%)$ & $32(68.1 \%)$ & 0.491 \\
\hline $\begin{array}{l}\text { Temporal artery biopsy positive } n=13 \text {, no. } \\
\text { of patients }\end{array}$ & $5(38.5 \%)$ & $5(50 \%)$ & $0(0 \%)$ & 0.231 \\
\hline $\begin{array}{l}{ }^{18} \text { F-FDG-PET/CT positive } n=14, \text { no. of } \\
\text { patients }\end{array}$ & $7(50 \%)$ & $5(62.5 \%)$ & $2(33.3 \%)$ & 0.592 \\
\hline Fulfilling 1990 GCA criteria, no. of patients & $16(25 \%)$ & $8(47.1 \%)$ & $8(17 \%)$ & 0.022 \\
\hline $\begin{array}{l}\text { PMR diagnosis before US examination, no. } \\
\text { of patients }\end{array}$ & $21(32.8 \%)$ & $4(23,5 \%)$ & $17(36,2 \%)$ & 0.386 \\
\hline Headache, no. of patients & $31(48.4 \%)$ & $12(70.6 \%)$ & $19(40.4 \%)$ & 0.033 \\
\hline Jaw claudication, no. of patients & $12(18.8 \%)$ & $9(52.9 \%)$ & & $<0.001$ \\
\hline Ocular ischaemia, & $4(6.3 \%)$ & $2(11.8 \%)$ & $2(4.3 \%)$ & 0.285 \\
\hline $\begin{array}{l}\text { Abnormal TA clinical examination, no. of } \\
\text { patients }\end{array}$ & $5(7.8 \%)$ & $3(17.6 \%)$ & $2(4.3 \%)$ & 0.112 \\
\hline CRP (mg/dL), median (IQR) & $1.7(0-6.5)$ & $7(2.1-14)$ & $1.1(0-5.1)$ & 0.001 \\
\hline $\operatorname{ESR}(\mathrm{mm} / \mathrm{h})$, mean $(\mathrm{SD})$ & $52.8(34.6)$ & $68.3(33.3)$ & $46.8(33.3)$ & 0.044 \\
\hline Haemoglobin (g/dL), mean (SD) & $12.5(1.7)$ & $11.8(1.6)$ & $12.7(1.7)$ & 0.059 \\
\hline Platelets $10^{9} / \mathrm{L}$, mean (SD) & $\begin{array}{c}276.1 \\
(105.8)\end{array}$ & $\begin{array}{c}323.4 \\
(116.3)\end{array}$ & $258.7(97.3)$ & 0.52 \\
\hline Positive US findings, no. of patients & $17(26.6 \%)$ & $15(88.2 \%)$ & $2(4.3 \%)$ & $<0.001$ \\
\hline $\begin{array}{l}\text { Temporal artery positive US findings, no. } \\
\text { of patients }\end{array}$ & $13(20.3 \%)$ & $12(70.6 \%)$ & $1(2.1 \%)$ & $<0.001$ \\
\hline Axillary positive US findings, no. of patients & $9(14.1 \%)$ & $8(47.1 \%)$ & $1(2.1 \%)$ & $<0.001$ \\
\hline $\begin{array}{l}\text { Subclavian positive US findings, no. of } \\
\text { patients }\end{array}$ & $5(7.8 \%)$ & $5(29.4 \%)$ & $0(0 \%)$ & $<0.001$ \\
\hline $\begin{array}{l}\text { Temporal artery + axillary or subclavian } \\
\text { positive US findings, no. of patients }\end{array}$ & $5(7.9 \%)$ & $5(29.4 \%)$ & $0(0 \%)$ & 0.003 \\
\hline Halo Count, median (IQR) & $0(0-0.75)$ & $2(1-4.5)$ & $0(0-0)$ & $<0.001$ \\
\hline Halo Score, median (IQR) & $0(0-4.5)$ & $18(7-22.5))$ & $0(0-0)$ & $<0.001$ \\
\hline Modified Halo Score, median (IQR) & $0(0-2.75)$ & $8(3-13.5)$ & $0(0-0)$ & $<0.001$ \\
\hline
\end{tabular}

Conclusion: The inclusion of subclavian arteries examination in the modified Halo Score does not improve the diagnostic accuracy of GCA. Nevertheless, it correlates better with markers of systemic inflammation in LV-GCA

Disclosure of Interests: None declared

DOI: 10.1136/annrheumdis-2021-eular.3129

\section{POS0813 FERTILITY AND PREGNANCY OUTCOMES IN TAKAYASU'S ARTERITIS}

A. Taghiyeva ${ }^{1}$, L. Kılıç ${ }^{2}$, M. Cagan ${ }^{3}$, E. C. Bolek ${ }^{2}$, G. K. YardımcI ${ }^{2}$, O. Karadag ${ }^{2}$, O. Ozyuncu ${ }^{3}$, S. A. Bilgen ${ }^{2}{ }^{1}{ }^{1}$ Hacettepe University Faculty of Medicine, İnternal Medicine, Ankara, Turkey; ${ }^{2}$ Hacettepe University Faculty of Medicine, Department of Internal Diseases Rheumatology, Ankara, Turkey; ${ }^{3}$ Hacettepe University Faculty of Medicine, Department of Obstetrics and Gynecology, Ankara, Turkey

Background: Takayasu's arteritis (TA) is commonly seen in women of childbearing ages; therefore, reproductive health of TA patients is an important issue.

Objectives: We aimed to evaluate the fertility and pregnancy $(\mathrm{PG})$ outcomes of TA patients before and after diagnosis.

Methods: In the prospective database of the Hacettepe University Vasculitis Research Centre (HUVAC), 202 TA patients (female $=184$ ) meeting the 1990 ACR criteria were registered by the end of February 2020. 120 patients who could be reached out gynaecological records and marriage status, were included in the study. We identified 233 PG in 82 of included these 120 TA patients (Figure 1). Demographic and clinical features, comorbidities, distribution of vascular involvement, obstetrical histories and outcomes were retrospectively evaluated. Patients were classified according to a novel proposed disease clusters (C1: Abdominal Predominant, C2: Aortic Arch Predominant, C3: Focal Disease) using the defined decision tree.

Results: 12 of 96 (12.5\%) married TA patients had infertility being defined as not being able to get pregnant after one year (or longer) of unprotected sex. $20(16.7 \%)$ women had menopause before the age of 45 , being defined as early menopause (EM). Compared to normal population, infertility ( $12.5 \%$ vs. $8.1 \%$ ) and EM ratios (16.7\% vs. $7.6 \%$ ) seem to be increased in TA patients $(1,2)$

200 PG had occurred before TA diagnosis (bTA) in 71 women, and 33 PG were observed after TA diagnosis (aTA) diagnosis in 19 women (two patients diagnosed during $P G$ ). According to novel disease subsets, aTA patients classified into $\mathrm{C} 1(n=3 ; 15.7 \%), \mathrm{C} 2(n=9 ; 47.3 \%)$ and C3 $(n=6 ; 31.5 \%)$. One patient could not be classified.

GHT was seen in 4 (12.1\%) patients being the most frequent maternal complication in aTA group. Most common fetal complications were prematurity, IUGR and LBW in both groups (Table 1). Even fetal complications were more frequent in aTA group, it was not statistically significant [11 (33.3\%) vs. 43 (21.5\%), $p=0.18$ respectively]. However, maternal complications were sig nificantly more common in aTA group $[22(11.0 \%)$ vs. $8(24.2 \%), p=0.048]$. There was no difference for the obstetrical outcomes in terms of novel TA classification.

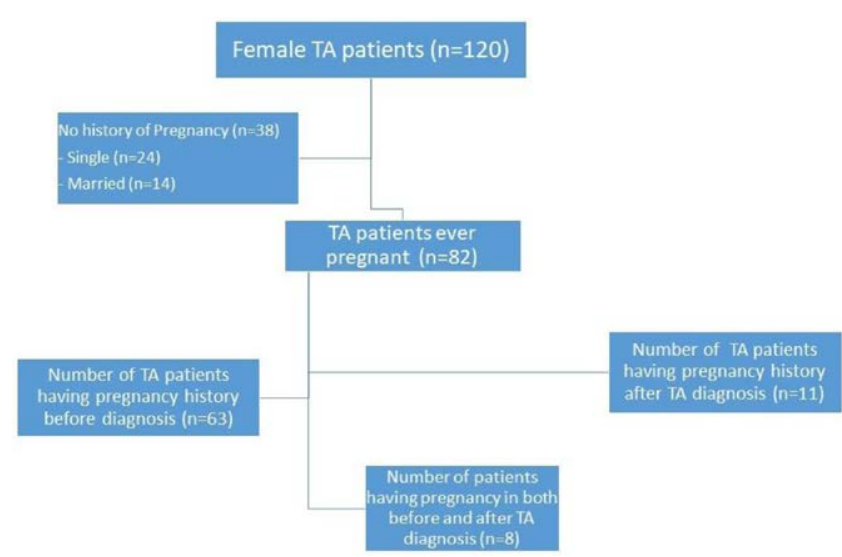

Conclusion: This study showed increased infertility and EM ratios in TA patients. PG of aTA had more complications in terms of maternal complications. Fetal complications were more frequent in PG of aTA but not statistically significant. Larger cohort data is required. 